\title{
Identification and assessment of differentially expressed genes involved in growth regulation in Apostichopus japonicus
} \author{
T.W. $\mathbf{L i}^{1,2}$ \\ ${ }^{1}$ School of Marine Sciences, Ningbo University, Ningbo, \\ Zhejiang Province, China \\ ${ }^{2}$ Ningbo City College of Vocational Technology, Ningbo, \\ Zhejiang Province, China \\ Corresponding author: C.H. Li \\ E-mail: chli@yic.ac.cn
}

L. Zhu' ${ }^{1}$, C.H. Li ${ }^{1}$, X.R. Su${ }^{1}$, C.Y. Guo ${ }^{1}$, Z. Wang ${ }^{1}$, C.H. Jin ${ }^{1}$, Y. Li ${ }^{1}$ and

Genet. Mol. Res. 12 (3): 3028-3037 (2013)

Received January 7, 2013

Accepted June 18, 2013

Published August 20, 2013

DOI http://dx.doi.org/10.4238/2013.August.20.4

\begin{abstract}
Rapid and efficient growth is a major consideration and challenge for global mariculture. The differential growth rate of the sea cucumber, Apostichopus japonicus, has significantly hampered the total production of the industry. In the present study, forward and reverse suppression subtractive hybridization libraries were constructed and sequenced from a fast-growth group and a slow-growth group of the sea cucumber. A total of 142 differentially expressed sequence tags (ESTs) with insertions longer than $150 \mathrm{bp}$ were identified and further analyzed. Fifty-seven of these ESTs (approximately 40\%) were functionally annotated for cell structure, energy metabolism, immunity response, and growth factor categories. Six candidate genes, arginine kinase, cytochrome $c$ oxidase subunit I, HSP70, $\beta$-actin, ferritin, and the ADP-ribosylation factor, were further validated by quantitative PCR. Significant differences were found between the fast- and slow-growth groups $(\mathrm{P}<0.05)$ for the expression levels of arginine kinase, cytochrome
\end{abstract}


$c$ oxidase, HSP70, the ADP-ribosylation factor, and $\beta$-actin. However, no significant difference was observed for ferritin. Our results provide promising candidate gene markers for practical size screening, and also further promote marker-assisted selective breeding of this species.

Key words: Apostichopus japonicus; Growth rate; qPCR; Suppression subtractive hybridization

\section{INTRODUCTION}

Aquaculture of the sea cucumber, Apostichopus japonicus (Echinodermata; Holothuroidea), has grown rapidly in recent years and is becoming one of the largest industries in Chinese mariculture. As a rough estimate, the species culture area in China exceeds 1 million acres, with a production value of over 150 million dollars in 2009 (Wang et al., 2009; Liu et al., 2010). To improve the productivity of the industry, the growth phenotype has received considerable attention by researchers, who have determined optimal conditions for growth with respect to temperature (An et al., 2007), nutrition (Yuan et al., 2006; Liu et al., 2009), and salinity (Yuan et al., 2010). However, to the best of our knowledge, the manipulation of growth traits has rarely been investigated in sea cucumber.

The identification and characterization of growth-related genes are the first step in such efforts, and different strategies such as cDNA libraries, homology cloning, and proteomics have been successfully utilized in some previous cases (Wu et al., 2009; Natarajascenivasan et al., 2011; Lenz et al., 2011). Suppression subtractive hybridization (SSH) combines normalization and subtraction in a single procedure, thus allowing the isolation of differentially expressed cDNA that is overexpressed in one population but not in another. In recent years, SSH has been successfully applied as an efficient method to identify differentially expressed genes in oyster (Renault et al., 2011), shrimp (He et al., 2004; Pan et al., 2005; Zhao et al., 2007; James et al., 2010), clam (Prado-Alvarez et al., 2009), and fish (Cui et al., 2011; Li et al., 2011b). However, these studies all focused on the identification of immune-related genes with the challenge of specific pathogens. Indeed, according to literature searches, SSH has rarely been used to analyze growth-related genes.

The goals of the present study were as follows: 1) to construct an SSH library for different growth rates in sea cucumber; 2 ) to screen and sequence the differentially expressed gene fragments; 3 ) to validate the expression profiles of certain candidate genes using quantitative PCR (qPCR).

\section{MATERIAL AND METHODS}

\section{Experimental animals}

Juvenile A. japonicus individuals were obtained from Shandong Oriental Ocean SciTech Co., Ltd., in October 2011. Individuals of similar sizes $(85 \pm 10 \mathrm{~g})$ were selected and cultured at the Ningbo Bowang Aquaculture Company for 5 months. Fifty experimental specimens were randomly selected and cultured in the laboratory for 1 week and then assigned to the following groups, according to their body weight: a fast-growth group (FGG), with a body 
weight of $358 \pm 35 \mathrm{~g}$, and a slow-growth group (SGG), with a body weight of $158 \pm 20 \mathrm{~g}$. The muscles from 10 sea cucumbers from each group were sheared, mixed together, and then ground into a fine powder using liquid nitrogen for the subsequent RNA extraction.

\section{Construction of SSH libraries}

The total RNA from the muscle was extracted according to the Trizol protocol (Invitrogen), and cDNA was obtained from $5 \mu \mathrm{g}$ total RNA using the SMART PCR cDNA Synthesis Kit (Clontech). The SSH assay was then performed with the PCR-Select cDNA Subtraction Kit (Clontech), following manufacturer instructions. Briefly, the cDNA from the FGG was considered as the tester and that from the SGG as the driver, for the forward subtraction; the reverse library was constructed using cDNA from the SGG as the tester and that from the FGG as the driver. The subtracted cDNA pools obtained from the PCR selection protocol were cloned into the pMD-18T vector to generate the SSH libraries in Escherichia coli DH5 $\alpha$. White colonies were randomly picked and cultured in Luria-Bertani broth at $37^{\circ} \mathrm{C}$ for $4-5 \mathrm{~h}$, and were further validated by PCR using M13 forward and reverse primers (Table 1). The positive clones were sequenced by Invitrogen (Shanghai).

Table 1. Primer sequences used in the present study.

\begin{tabular}{lll}
\hline Primer & Sequence (5'-3') & Product size (bp) \\
\hline M13-47 & GTCGTGACTGGGAAAACCCTGGCG & \\
RV-M & GAGCGGATAACAATTTCACACAGG & \\
PCR primer 1 & CTAATACGACTCACTATAGGGC & \\
Nested PCR primer 1 & TCGAGCGGCCGCCCGGGCAGGT & \\
Nested PCR primer 2R & AGCGTGGTCGCGGCCGAGGT & \\
18 s-F & CGAGTCGTGGGAGATTTTT & 198 \\
18 s-R & CACTTTGGCTGCTTTGAAC & \\
FSSH 3-F & TCATGGTAGCTGCTGTGAAGTAGG & 234 \\
FSSH 3-R & ACTTGTTCTGATTCTTCGGACACC & \\
FSSH 30-F & CAGATGGGAGGAGACATGAAGGA & 139 \\
FSSH 30-R & TGGATGGGCAAGTCAGAACAAATC & \\
FSSH 17-F & CTGCTGGATGCTTTCAAGGT & 133 \\
FSSH 17-R & CTGTTCCGTCAGGTAGTGGG & \\
FSSH 28-F & TTG TACGCCAACACTGTTCTT & 175 \\
FSSH 28-R & GCCAGACTCGTCGTATTCCT & \\
FSSH 37-F & AACGAATCTAAAATCATTAGTCAGTG & 247 \\
FSSH 37-R & CTACTATTGCTTGGAAAACGAGA & \\
FSSH 122-F & CCAAGAGAACATTGTCAAGC & 220 \\
FSSH 122-R & ATTCGAGTCGAACCTCCG & \\
\hline
\end{tabular}

\section{Sequencing analysis}

The sequences were analyzed using the BLAST algorithm on the National Center for Biotechnology Information website (http://www.ncbi.nlm.nih.gov/blast) after removal of the adapter and contaminating vector sequences. The deduced amino acid sequences were analyzed using the Expert Protein Analysis System (http://www.expasy.org/).

\section{Confirmation of differentially expressed sequence tags (ESTs) by qPCR}

Sea cucumbers of various sizes, ranging from 105 to $320 \mathrm{~g}$, at the same growth stage 
were collected from the indoor ponds of the Pulandian Hatchery in Dalian, China, in April 2012 and were divided into 2 groups for RNA extraction. Muscle tissue was removed and prepared for RNA extraction. First-strand cDNA synthesis was performed based on the Promega M-MLV RT user information (Promega) using total RNA treated with DNase I (Promega) as the template. The cDNA mix was diluted 1:50 for the subsequent experiment. There were 6 replicates for each group.

Six candidate genes, arginine kinase, cytochrome $c$ oxidase, HSP70, $\beta$-actin, ferritin, and the ADP-ribosylation factor, were selected to validate the efficiency of the SSH library. The gene-specific primers for each differentially expressed gene are shown in Table 1. A pair of 18S RNA primers (Table 1) was used to amplify a 196-bp product, which served as the internal control. The real-time PCR amplification was performed using a Rotor-Gene 6000 real-time PCR detecting system. The reaction was performed in a total volume of $20 \mu \mathrm{L}$ containing $10 \mu \mathrm{L} 2 \mathrm{X}$ SYBR Green Master Mix (Takara), $4 \mu \mathrm{L}$ diluted cDNA mixture, $1 \mu \mathrm{L}$ each primer $(10 \mu \mathrm{M})$, and $4 \mu \mathrm{L}$ diethylpyrocarbonate-treated water. The thermal profile for the real-time PCR was $94^{\circ} \mathrm{C}$ for $2 \mathrm{~min}$, followed by 45 cycles of $94^{\circ} \mathrm{C}$ for $15 \mathrm{~s}, 56^{\circ} \mathrm{C}$ for $20 \mathrm{~s}$, and $72^{\circ} \mathrm{C}$ for $20 \mathrm{~s}$. A dissociation curve analysis of the amplification products was performed at the end of each PCR to confirm that only a single PCR product was amplified and detected. The $2^{-\Delta \Delta C T}$ method was used to analyze the expression level of the differentially expressed genes. The cycle threshold $(\mathrm{Ct})$ for the target amplified genes and the $\mathrm{Ct}$ for the internal control were determined for each sample. The difference in the $\mathrm{Ct}$ for the target and the internal control, called $\Delta \mathrm{CT}$, was calculated to normalize the differences in the amount of template and the efficiency of the RT-PCR. The $\Delta$ CT value for the SGG sample was used as the reference sample, henceforth referred to as the calibrator. The $\Delta \mathrm{CT}$ for each sample was subtracted from the $\Delta \mathrm{CT}$ of the calibrator, and this difference was called the $\Delta \Delta \mathrm{CT}$. The expression levels of differentially expressed genes were calculated using the $2^{-\Delta \Delta C T}$ method, and the value obtained was denoted the $\mathrm{n}$-fold difference relative to the calibrator. All data are reported in terms of relative mRNA expression as means $\pm \mathrm{SD}$. The data were subjected to one-way analysis of variance (ANOVA). $\mathrm{P}$ values $<0.05$ or $<0.01$ were considered to be significant.

\section{RESULTS}

\section{SSH construction and EST sequencing}

Two subtracted cDNA libraries (forward and reverse libraries) were constructed in this study. There was an obvious difference between the subtracted and unsubtracted groups based on the results of the agarose gel electrophoresis of the secondary PCR products (Figure 1). The PCR screening revealed that the size of the inserted cDNA fragments ranged from 200 to $900 \mathrm{bp}$ (Figure 2). Eighty-seven and 82 clones were randomly selected for sequencing from the forward and reverse libraries, respectively. A total of 151 sequences were successfully generated, and 142 sequences with insertions longer than $150 \mathrm{bp}$ were used in the sequence homology search. Approximately half of the products did not exhibit sufficient homology with any known genes (Figure 3). More than $40 \%$ of the ESTs were identified and functionally annotated in the gene categories for respiratory metabolism (cytochrome $c$ oxidase subunit I), membrane structure ( $\beta$-actin and filamin), energy metabolism (arginine kinase and ADP-ribosylation factor), and growth factor [fibroblast growth factor (FGF) receptor-like 1 
precursor, and vascular endothelial growth factor (VEGF) $\mathrm{C}$ precursor]. Some of these genes demonstrated more than 1 copy in the library (Tables 2 and 3), namely $\beta$-actin, arginine kinase, the ADP-ribosylation factor, and cytochrome $c$ oxidase subunit I. Importantly, some candidate genes were detected for the first time, to the best of our knowledge, in sea cucumber, including the VEGF C precursor, the ADP-ribosylation factor, and the FGF receptor-like 1 precursor.

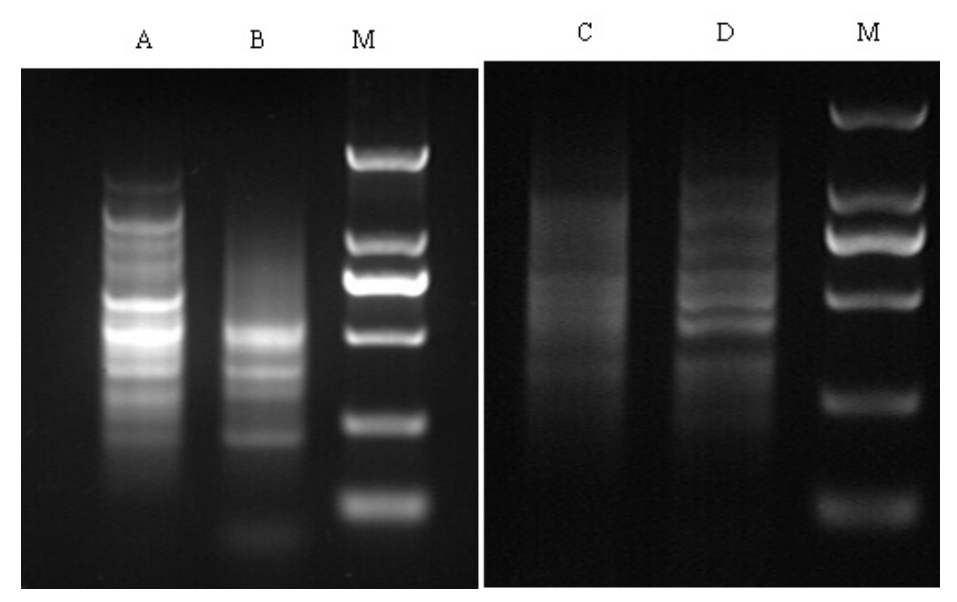

Figure 1. Secondary PCR products of the subtracted library. Lane $A=$ unsubtracted sample for the forward library. Lane $B=$ subtracted sample for the forward library. Lane $C=$ unsubtracted sample for the reverse library. Lane $D$ = subtracted sample for the reverse library. Lane $M=$ DL2000 DNA marker.

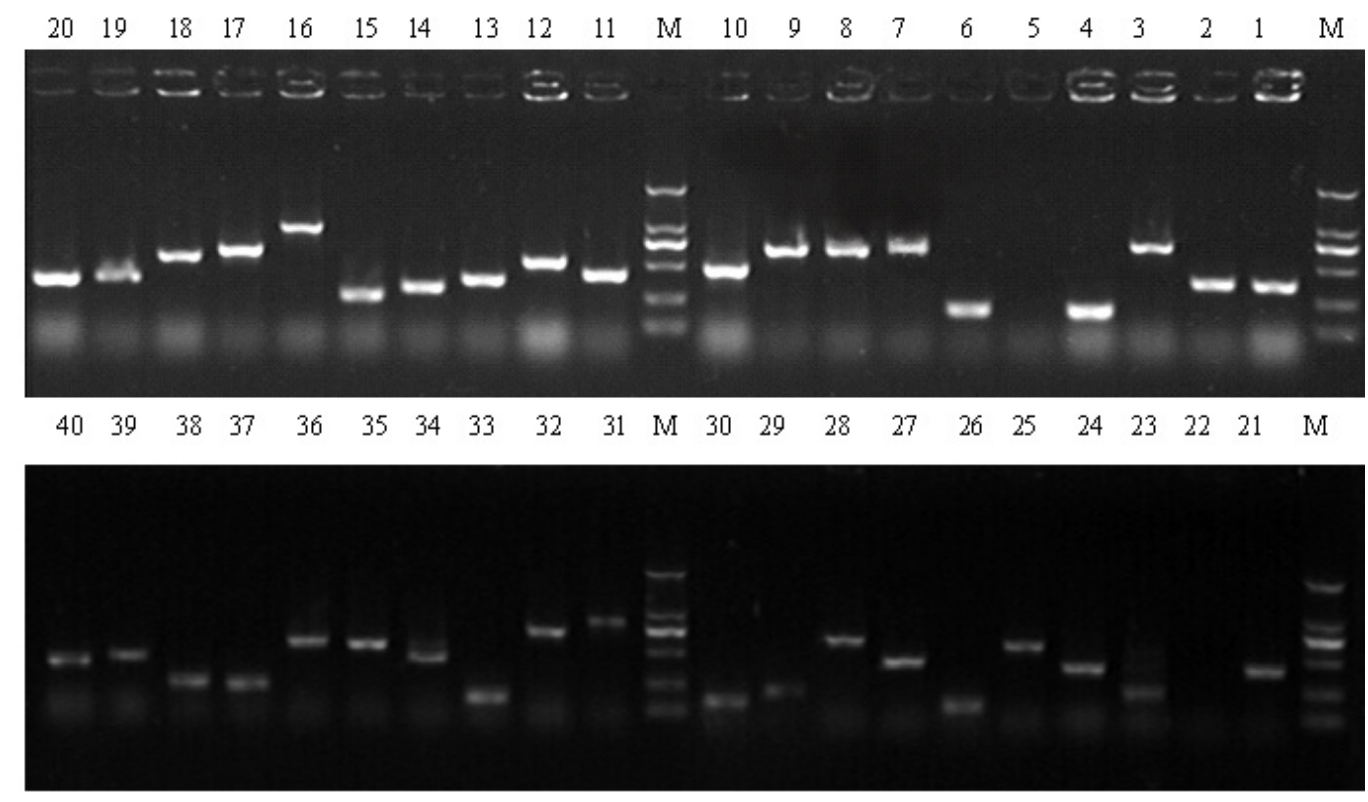

Figure 2. Analysis of the cDNA inserts by PCR amplification using M13 primers. Lane $M=$ DL2000 marker. Lane $1-40=$ PCR products from 40 different colonies. 

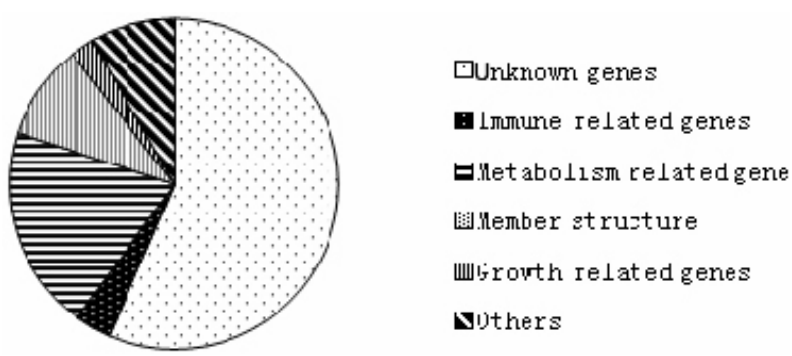

Figure 3. Functional annotation of the sequenced clones from the SSH libraries.

Table 2. Distribution of differentially expressed genes from the forward SSH library.

\begin{tabular}{|c|c|c|c|c|c|}
\hline Clone ID & Identification clones & Accession No. & Species & Identities & Redundancy \\
\hline FSSH 3 & Cytochrome $c$ oxidase subunit I & JN836336.1 & Apostichopus japonicus & $99 \%$ & 3 \\
\hline FSSH 4 & Casein kinase 1 , delta & XP_002167634.1 & Hydra magnipapillata & $29 \%$ & 1 \\
\hline FSSH 10 & Metalloprotease family M12A & XP_-002902411.1 & Phytophthora infestans & $31 \%$ & 1 \\
\hline FSSH 17 & Ferritin mRNA & DQ058411.1 & Apostichopus japonicus & $99 \%$ & 1 \\
\hline FSSH 18 & Filamin & XP_792145.2 & Strongylocentrotus purpuratus & $81 \%$ & 1 \\
\hline FSSH 20 & Hypothetical protein, conserved & CBH18507.1 & Trypanosoma brucei gambiense & $38 \%$ & 1 \\
\hline FSSH 22 & $\begin{array}{l}\text { APC family amino acid- } \\
\text { polyamine-organocation transporter }\end{array}$ & YP_001485465.1 & Bacillus pumilus & $45 \%$ & 1 \\
\hline FSSH 24 & $\begin{array}{l}\text { Vascular endothelial growth factor } \\
\text { C precursor }\end{array}$ & XP_002159836.1 & Hydra magnipapillata & $64 \%$ & 1 \\
\hline FSSH 28 & $\beta$-actin & EU668024.1 & Apostichopus japonicus & $99 \%$ & 7 \\
\hline FSSH 30 & Arginine kinase & AB025275.1 & Apostichopus japonicus & $99 \%$ & 5 \\
\hline FSSH 37 & ADP-ribosylation factor & XP 002260453.1 & Plasmodium knowlesi strain $\mathrm{H}$ & $9.3 \%$ & 2 \\
\hline FSSH 44 & $\begin{array}{l}\text { Fibroblast growth factor } \\
\text { receptor-like } 1 \text { precursor }\end{array}$ & NP_001165523.1 & Strongylocentrotus purpuratus & $59 \%$ & 1 \\
\hline FSSH 45 & CRISPR-associated RAMP protein & YP 003615800.1 & Methanocaldococcus infernus $\mathrm{ME}$ & $40 \%$ & 1 \\
\hline FSSH 47 & $\mathrm{ABC}$ transporter & XP_001350233.1 & Plasmodium falciparum & $29 \%$ & 1 \\
\hline FSSH 72 & Nbs-lrr resistance protein & XP_003615790.1 & Medicago truncatula & $54 \%$ & 1 \\
\hline FSSH 81 & Myosin-15, putative & XP_002785699.1 & Perkinsus marinus & $35 \%$ & 1 \\
\hline FSSH 103 & Red-type mitochondrial DNA & $\mathrm{AB} \overline{5} 25761.1$ & Apostichopus japonicus & $99 \%$ & 1 \\
\hline FSSH 112 & 185-kDa silk protein & AAA99803.1 & Chironomus pallidivittatus & $41 \%$ & 1 \\
\hline FSSH 116 & Cell wall-associated hydrolase & CCB82302.1 & Lactobacillus pentosus $\mathrm{MP}-10$ & $49 \%$ & 1 \\
\hline FSSH 122 & Heat shock protein 70 & EU930813.1 & Apostichopus japonicus & $99 \%$ & 2 \\
\hline
\end{tabular}

Table 3. Distribution of differentially expressed genes from the reverse SSH library.

\begin{tabular}{|c|c|c|c|c|c|}
\hline Clone ID & Identification clones & Accession No. & Species & Identities & Redundancy \\
\hline RSSH 2 & Exonuclease domain & CBK94522.1 & Eubacterium rectale & $33 \%$ & 1 \\
\hline RSSH 5 & Cadherin-5-like & XP_003417144.1 & Loxodonta africana & $42 \%$ & 1 \\
\hline RSSH10 & Serpentine receptor & $\mathrm{NP}^{-} 504761.2$ & Caenorhabditis elegans & $37 \%$ & 1 \\
\hline RSSH 21 & HMG176 isoform D & AEĀ76318.1 & Mamestra configurata & $40 \%$ & 1 \\
\hline RSSH 22 & Hypothetical protein SPW 4421 & ZP_09404117.1 & Streptomyces sp W007 & $33 \%$ & 1 \\
\hline RSSH 25 & $\begin{array}{l}\text { Very long-chain acyl-CoA synthetase } \\
\text { isoform } 1\end{array}$ & XP_001336957.1 & Danio rerio & $52 \%$ & 3 \\
\hline RSSH 27 & Bifunctional inhibitor/lipid-transfer protein & NP_174848.1 & Arabidopsis thaliana & $35 \%$ & 1 \\
\hline RSSH 33 & Sucrose-6-phosphate hydrolase & $\mathrm{ZP}^{-} 07823322.1$ & Streptococcus pseudoporcinus & $36 \%$ & 1 \\
\hline RSSH 55 & NADH dehydrogenase subunit A & ZP_06591397.1 & Streptomyces albus & $38 \%$ & 2 \\
\hline RSSH 58 & CorA-like protein & ZP_08244847.1 & Streptococcus parauberis & $34 \%$ & 1 \\
\hline RSSH 70 & LOC100004228 protein & AAI 17651.1 & Danio rerio & $52 \%$ & 1 \\
\hline RSSH 75 & GL27217 & XP 002023794.1 & Drosophila persimilis & $65 \%$ & 1 \\
\hline RSSH 76 & CG4168 & AAF 53442.5 & Drosophila melanogaster & $38 \%$ & 1 \\
\hline RSSH 91 & $\begin{array}{l}\text { Fibronectin type-III domain-containing } \\
\text { protein } 3 \mathrm{~A}\end{array}$ & XP_787929.2 & Strongylocentrotus purpuratus & $64 \%$ & 2 \\
\hline RSSH 106 & THAP domain-containing 10-like & XP 002737779.1 & Saccoglossus kowalevskii & $38 \%$ & 1 \\
\hline RSSH 132 & NADH dehydrogenase subunit 5 & YP_004347529.1 & Megacopta cribraria & $40 \%$ & 2 \\
\hline RSSH 143 & $\begin{array}{l}\text { Novel protein with an immunoglobulin } \\
\text { V-set domain }\end{array}$ & CAX 13578.1 & Danio rerio & $28 \%$ & 1 \\
\hline RSSH147 & Filamin isoform A & AAG43431.1 & Drosophila melanogaster & $68 \%$ & 1 \\
\hline
\end{tabular}




\section{Expression patterns for differentially expressed genes}

To confirm the results of the subtracted libraries, 6 ESTs were selected for expression profile analysis using qPCR. Overexpression of 5 genes was observed in the FGG, whereas a downregulation expression profile was only identified for ferritin (Figure 4). ANOVA revealed significant differences for arginine kinase, cytochrome $c$ oxidase, HSP70, the ADPribosylation factor, and actin between growth groups. However, no significant difference was observed for ferritin.
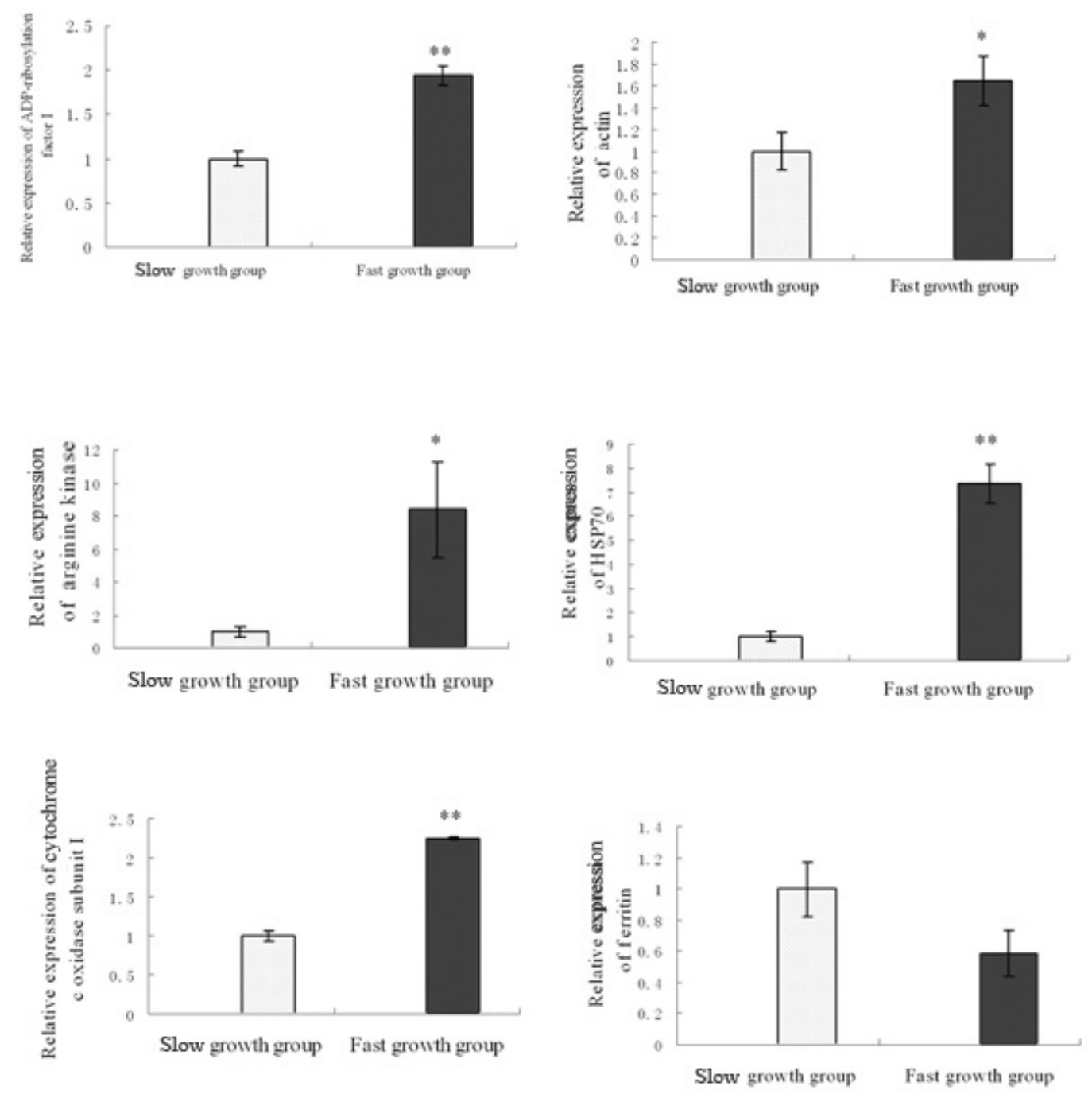

Figure 4. Expression profiles of six selected candidate genes by qPCR using $18 \mathrm{~S}$ rRNA as the internal control. Each symbol and vertical bar represents the mean $\pm \mathrm{SD}(\mathrm{N}=6)$. Significant differences from the control are $* \mathrm{P}<$ 0.05 and $* * \mathrm{P}<0.01$. 


\section{DISCUSSION}

As one of the most powerful methods for isolating differentially expressed genes, SSH has been successfully applied for a variety of organisms. In the present study, growthrelated genes were investigated and characterized in sea cucumbers exhibiting fast-growth and slow-growth phenotypes. A total of 57 matched ESTs were annotated and divided into 6 categories. Six candidate genes were randomly selected and further evaluated using qPCR, with 5 genes showing significant upregulation compared to the control group (Figure 4).

Unexpectedly, $\beta$-actin was the most frequently encountered molecule, with 7 redundancies in our 142 sequencing samples. Significant differences in $\beta$-actin expression between the FGG and SGG were also confirmed by a quantitative analysis, implying that it participated in the regulation of sea cucumber growth. This finding was consistent with the fact that $\beta$-actin plays important roles in the structure of the cytoskeleton, cell division and motility, and muscle contraction by facilitating the ubiquitination/degradation of the growth hormone receptor (Rico-Bautista et al., 2004; Zhu et al., 2005). In addition to $\beta$-actin, 2 growth-related genes validated in other species were also identified in our study: FGF and VEGF. These candidates were not included in subsequent expression analyses due to failure in designing effective primers for qPCR. In higher animals, FGFs have been demonstrated to promote the proliferation, growth, and regeneration of different cells as a powerful mitogen (Baird, 1994). On the other hand, VEGF plays a central role in the maintenance of the human vascular system (Tammela et al., 2005) and promotes the formation of endothelial permeability fibers and cellular elongation in mammals (Ferrara, 1999). Considering that little is known about the function of FGFs or VEGF in regulating A. japonicus growth, our future study will address how these molecules might regulate the growth of sea cucumber, focusing on their expression profiles during different developmental stages.

Many studies have revealed connections between growth and energy metabolism (Stelling et al., 2002; Picha et al., 2009; Overturf et al., 2010). To achieve efficient growth, organisms have evolved a finely tuned mechanism to tightly balance energy partitioning and nutrient utilization. Energy metabolism-related enzymes are also considered to be of major importance in regulating growth. Along with the Ras superfamily of regulatory GTPases, the ADP ribosylation factor is part of the Arf family of proteins. These proteins are involved in a diverse spectrum of cellular activities, including regulating cell growth and signal transduction, the organization of the cytoskeleton, the maintenance of organelle structures, and regulating membrane trafficking along the exocytic and endocytic pathways (Sebald et al., 2003; Donaldson and Honda, 2005; D'Souza-Schorey and Chavrier, 2006; Myers and Casanova, 2008). In yeast, the disruption of ARF1 resulted in slow growth and cold sensitivity (Stearns et al., 1990). Another key energy metabolism factor, arginine kinase, belongs to a class of kinases that play roles in the maintenance of ATP levels through the phosphorylation of so-called "phosphagens", which then serve as high-energy sources from which ATP can be rapidly replenished (Pereira et al., 2000).

There has been some evidence that immunity genes are also important components in growth regulation. Ferritin plays a key role in cellular iron metabolism, which includes iron storage and detoxification, processes that have been documented in A. japonicus (Li et al., 2011a). Recently, more attention has been paid to the involvement of ferritin in the immunological defense system under external stress (Cullen et al., 2000). Ferritin can protect organ- 
isms by sequestering heavy metals (He et al., 2009). Similar to ferritin, HSP70 plays essential roles in protein metabolism under both normal and stressed conditions (Kiang and Tsokos, 1998). The expression of HSP70 was induced by heat and also by the exposure to insecticides and heavy metals, such as cadmium and copper (Yoshimi et al., 2009). Heavy metals could damage the physical performance of sea cucumber and lead to growth retardation, even resulting in death (Sun et al., 2009). The function of molecular chaperones may be to stabilize and protect growth-related proteins, resulting in the ultimate mediation of sea cucumber growth.

\section{ACKNOWLEDGMENTS}

Research supported by the Project of Science and Technology Innovation Creative Team in Zhejiang Province (\#2012R10025-09), the Natural Science Foundation of Ningbo (\#2011A61003 and \#2011C11001), the Spark Program of State Ministry (\#2011GA701019), and the K.C. Wong Magna Fund of Ningbo University.

\section{REFERENCES}

An Z, Dong Y and Dong S (2007). Temperature effects on growth-ration relationships of juvenile sea cucumber Apostichopus japonicus (Selenka). Aquaculture 272: 644-648.

Baird A (1994). Fibroblast growth factors: activities and significance of non-neurotrophin neurotrophic growth factors. Curr. Opin. Neurobiol. 4: 78-86.

Cui Z, Zhang K, Qu X and Liu Q (2011). Construction of differentially expressed genes library of bighead carp (Aristichthys nobilis) exposed to microcystin-lr using ssh and expression profile of related genes. Fish Shellfish. Immunol. 31: 746-753.

Cullen VC, Mackarel AJ, Hislip SJ, O'Connor CM, et al. (2000). Investigation of vascular endothelial growth factor effects on pulmonary endothelial monolayer permeability and neutrophil transmigration. Gen. Pharmacol. 35: 149-157.

D'Souza-Schorey C and Chavrier P (2006). ARF proteins: roles in membrane traffic and beyond. Nat. Rev. Mol. Cell Biol. 7: 347-358.

Donaldson JG and Honda A (2005). Localization and function of Arf family GTPases. Biochem. Soc. Trans. 33: 639-642.

Ferrara N (1999). Vascular endothelial growth factor: molecular and biological aspects. Curr. Top. Microbiol. Immunol. 237: 1-30.

He JJ, Li Y, Li TW, Su XR, et al. (2009). Construction of cDNA library with Tegillarca granosa muscular tissue and sequence analysis of ferritin gene. Oceanol. Limnol. Sin. 40: 289-295.

$\mathrm{He}$ N, Liu H and Xu X (2004). Identification of genes involved in the response of haemocytes of Penaeus japonicus by suppression subtractive hybridization (SSH) following microbial challenge. Fish Shellfish Immunol. 17: 121-128.

James R, Thampuran N, Lalitha KV, Rajan LA, et al. (2010). Differential gene expression profile of the hepatopancreas of white spot syndrome virus infected Fenneropenaeus indicus by suppression subtractive hybridization. Fish Shellfish Immunol. 29: 884-889.

Kiang JG and Tsokos GC (1998). Heat shock protein $70 \mathrm{kDa}$ : molecular biology, biochemistry, and physiology. Pharmacol. Ther. 80: 183-201.

Lenz T, Fischer JJ and Dreger M (2011). Probing small molecule-protein interactions: A new perspective for functional proteomics. J. Proteomics 75: 100-115.

Li CH, Cui J, Li Y, Zhou J, et al. (2011a). Cloning and characterization of ferritin gene from south cultured Stichopus japonicus. Oceanol. Limnol. Sin. 4: 567-572.

$\mathrm{Li} \mathrm{CH}$, Chen J, Shi YH and Lu XJ (2011b). Use of suppressive subtractive hybridization to identify differentially expressed genes in ayu (Plecoglossus altivelis) associated with Listonella anguillarum infection. Fish Shellfish Immunol. 31: 500-506.

Liu Y, Dong S, Tian X, Wang F, et al. (2009). Effects of dietary sea mud and yellow soil on growth and energy budget of the sea cucumber Apostichopus japonicus (Selenka). Aquaculture 286: 266-270.

Liu H, Zheng F, Sun X, Hong X, et al. (2010). Identification of the pathogens associated with skin ulceration and peristome tumescence in cultured sea cucumbers Apostichopus japonicus (Selenka). J. Invertebr. Pathol. 105: 236-242.

Myers KR and Casanova JE (2008). Regulation of actin cytoskeleton dynamics by Arf-family GTPases. Trends Cell Biol. 18: $184-192$.

Natarajaseenivasan K, Shanmughapriya S, Velineni S, Artiushin SC, et al. (2011). Cloning, expression, and homology 
modeling of GroEL protein from Leptospira interrogans serovar autumnalis strain N2. Genomics Proteomics Bioinform. 9: 151-157.

Overturf K, LaPatra S, Towner R, Campbell N, et al. (2010). Relationships between growth and disease resistance in rainbow trout, Oncorhynchus mykiss (Walbaum). J. Fish Dis. 33: 321-329.

Pan D, He N, Yang Z, Liu H, et al. (2005). Differential gene expression profile in hepatopancreas of WSSV-resistant shrimp (Penaeus japonicus) by suppression subtractive hybridization. Dev. Comp. Immunol. 29: 103-112.

Pereira CA, Alonso GD, Paveto MC, Iribarren A, et al. (2000). Trypanosoma cruzi arginine kinase characterization and cloning. A novel energetic pathway in protozoan parasites. J. Biol. Chem. 275: 1495-1501.

Picha ME, Strom CN, Riley LG, Walker AA, et al. (2009). Plasma ghrelin and growth hormone regulation in response to metabolic state in hybrid striped bass: effects of feeding, ghrelin and insulin-like growth factor-I on in vivo and in vitro GH secretion. Gen. Comp. Endocrinol. 161: 365-372.

Prado-Alvarez M, Gestal C, Novoa B and Figueras A (2009). Differentially expressed genes of the carpet shell clam Ruditapes decussatus against Perkinsus olseni. Fish Shellfish Immunol. 26: 72-83.

Renault T, Faury N, Barbosa-Solomieu V and Moreau K (2011). Suppression substractive hybridisation (SSH) and real time PCR reveal differential gene expression in the Pacific cupped oyster, Crassostrea gigas, challenged with Ostreid herpesvirus 1. Dev. Comp. Immunol. 35: 725-735.

Rico-Bautista E, Negrín-Martínez C, Novoa-Mogollón J, Fernández-Perez L, et al. (2004). Downregulation of the growth hormone-induced Janus kinase 2/signal transducer and activator of transcription 5 signaling pathway requires an intact actin cytoskeleton. Exp. Cell Res. 294: 269-280.

Sebald E, Krueger R, King LM, Cohn DH, et al. (2003). Isolation of a new member of the ADP-ribosylation like factor gene family, ARL8, from a cartilage cDNA library. Gene 311: 147-151.

Stearns T, Kahn RA, Botstein D and Hoyt MA (1990). ADP ribosylation factor is an essential protein in Saccharomyces cerevisiae and is encoded by two genes. Mol. Cell Biol. 10: 6690-6699.

Stelling J, Klamt S, Bettenbrock K, Schuster S, et al. (2002). Metabolic network structure determines key aspects of functionality and regulation. Nature 420: 190-193.

Sun ZX, Chen S, Chen J, Gao H, et al. (2007). Acute toxicity of four heavy metals acting on Apostichopus japonicus juvenile. Mar. Sci. Bull. 26: 80-85.

Sun ZX, Wang HE, Wang J, Liu JC, et al. (2009). Single and joint toxicity of mercury, cadmium and selenium on juvenile sea cucumber Apostichopus japonicus. Oceanol. Limnol. Sin. 40: 228-234.

Tammela T, Enholm B, Alitalo K and Paavonen K (2005). The biology of vascular endothelial growth factors. Cardiovasc. Res. 65: 550-563.

Wang Y, Leng M, Chen X, Rong X, et al. (2009). In vitro bacteriostatic effect of Chinese herbs against causative pathogens of skin ulcer syndrome in sea cucumber Apostichopus japonicus. Prog. Fish. Sci. 30: 1-7.

$\mathrm{Wu}$ XP, Fu BQ, Wang XL, Yu L, et al. (2009). Identification of antigenic genes in Trichinella spiralis by immunoscreening of cDNA libraries. Vet. Parasitol. 159: 272-275.

Yoshimi T, Odagiri K, Hiroshige Y, Yokobori S, et al. (2009). Induction profile of HSP70-cognate genes by environmental pollutants in Chironomidae. Environ. Toxicol. Pharmacol. 28: 294-301.

Yuan X, Yang H, Zhou Y, Mao Y, et al. (2006). The influence of diets containing dried bivalve feces and/or powdered algae on growth and energy distribution in sea cucumber Apostichopus japonicus (Selenka) (Echinodermata: Holothuroidea). Aquaculture 256: 457-467.

Yuan X, Yang H, Wang L, Zhou Y, et al. (2010). Effects of salinity on energy budget in pond-cultured sea cucumber Apostichopus japonicus (Selenka) (Echinodermata: Holothuroidea). Aquaculture 306: 348-351.

Zhao ZY, Yin ZX, Weng SP, Guan HJ, et al. (2007). Profiling of differentially expressed genes in hepatopancreas of white spot syndrome virus-resistant shrimp (Litopenaeus vannamei) by suppression subtractive hybridisation. Fish Shellfish Immunol. 22: 520-534.

Zhu XJ, Dai ZM, Liu J and Yang WJ (2005). Actin gene in prawn, Macrobrachium rosenbergii: characteristics and differential tissue expression during embryonic development. Comp. Biochem. Physiol. B Biochem. Mol. Biol. 140: 599-605. 